S T O RE

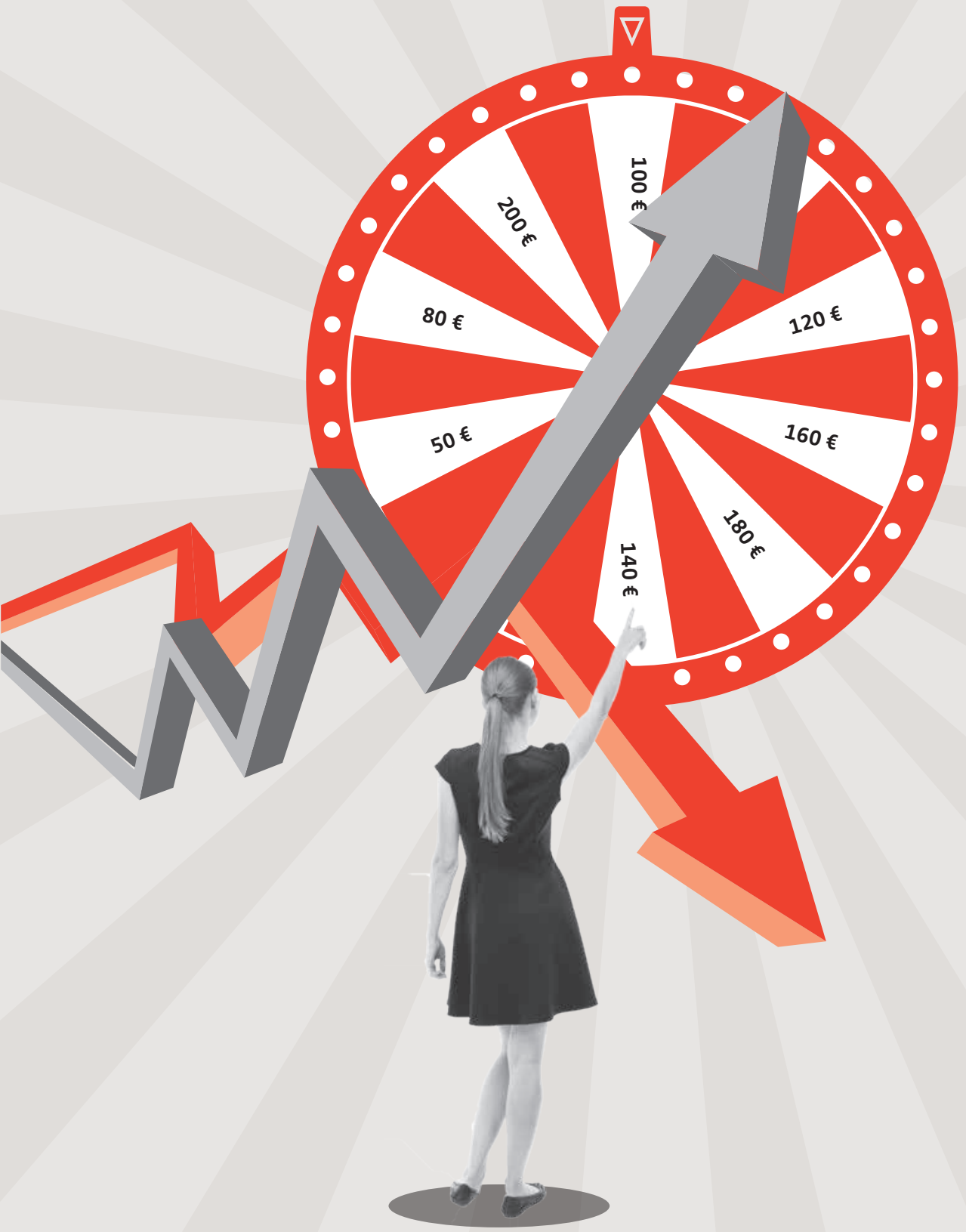




\title{
The Perils of Retail Price Differentiation: Why Nobody Wins When Customers Lose
}

\author{
Werner Reinartz and Nico Wiegand
}

\author{
$\square$ \\ KEYWORDS \\ Price Differentiation, Retailing, \\ Willingness-to-Pay, Price Fairness, \\ Consumer Behavior \\ THE AUTHORS \\ Werner Reinartz
}

Professor of Marketing, University of Cologne and Director of the Center for Research in Retailing (IFH),

Cologne, Germany

werner.reinartz@uni-koeln.de

Nico Wiegand

Assistant Professor in Marketing, University of Cologne, Germany wiegand@wiso.uni-koeln.de
The new pricing playground /// Retailers increasingly make use of differentiated prices in forms of coupons, sales promotions, and personalized offers. Especially in multichannel retailing it has become common practice to differentiate prices according to touchpoints or across online and offline channels. For example, prices for identical products are often lower on price comparison sites than when accessing the shop directly via its URL. Price differentiation comes in different forms. In general, retailers may charge different prices according to customer segments and/or sales channels as well as dynamically over time, or a combination of both (Figure 1 ).

With the growing availability of behavioral consumer data from online browsing and purchasing, businesses can even tailor product prices to consumers' individual willingnessto-pay. Simulations show that profit uplifts are much higher when such data is used compared to traditional consumer metrics like demographics. Besides, automated algorithms have made the implementation of pricing measures much cheaper and easier. It is thus not surprising that many companies are jumping on the bandwagon by experimenting with various forms of price differentiation.

Digitalization works both ways /// However, the same advances that enhance retailing's options to leverage price have also been a blessing for consumers. Price transparency at near zero search costs not only affects their sensitivity towards product prices but makes fencing - the supplier's attempt to shield consumer groups with different prices 
FIGURE 1:

\section{Different forms of price differentiation}

STATIC

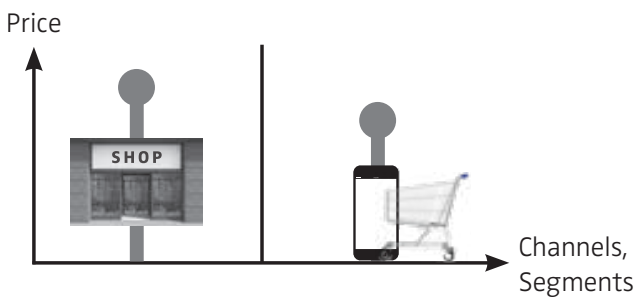

Different prices between segments and/or sales channels
DYNAMIC

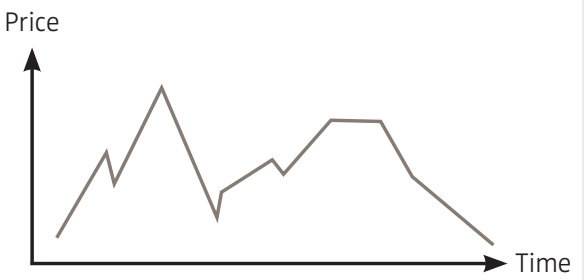

Different prices over time for the same or similar offers from each other - a difficult endeavor. Nowadays, betting on consumers' lack of awareness or even ignorance towards price differences does not seem like a sustainable strategy. In fact, our representative survey among German customers across three large product categories suggests that an overwhelming majority (91\%) obtained information about price ranges of the desired product prior to their purchase. Over $40 \%$ even confirmed very accurate price knowledge. This transparency paired with awareness of companies' differentiation practices makes consumers highly alert and sensitive to price changes, placing tight boundaries around overt differentiation schemes. We exposed over 2,000 German consumers to different forms of retail price differentiation in a large-scale experiment to empirically analyze how they react.

How consumers identify and evaluate the fairness of differentiated prices /// Even if both, companies and consumers, can benefit from price differentiation, consumers identifying these practices may feel discriminated. Our study showed that independent of whether consumers benefitted from a pricing scheme, $74.8 \%$ of consumers across six price differentiation schemes considered the shown difference as unfair. Among the beneficiaries, this number dropped only slightly to $65.2 \%$. This is likely because consumers may fear that a price differentiation scheme might be turned against them another time. To what extent consumers perceive price differentiation as fair or unfair depends on several criteria and on the types of price differentiation measures a company implements. Figure 2 summarizes the impact the different criteria have on trust in a retailer.

> How similar is the purchase situation? /// The less similar the purchase situation is, the less likely a different price is considered unfair. For example, a company can offer a basic, and a premium version of the same good. Additional services or features added to products, or different distribution channels reduce the perceived similarity. Also, the timing of price differentiation plays a role. From the consumer's viewpoint, it makes a difference whether, e.g. an available coupon expired just the day before or the last promotion was several months ago. If the difference is clear, offers tend to be classified as separate and not as a form of pure price differentiation. Overall, the dissimilarity of offers has a high impact on trust.

$>$ Can I decide which price to pay? /// If a good deal is accessible through extended search or other consumer action, consumers have some degree of control over the price they pay. Price-sensitive consumers are likely to incur 
greater effort and time to receive a good price, while less sensitive consumers may accept the higher price without much complaining when, for example, they need a product urgently or have little time. Our study showed that consumers who have more control, e.g., when they can use coupons or use a specific channel, their attitude and loyalty towards the retailer improves. However, more control by itself has a smaller effect on perceptions of fairness and behavioral consequences than other criteria. It seems, that consumers do not only base the evaluation on their own advantage, but also consider the effects on disadvantaged consumers. A feeling of solidarity with less knowledgeable people may induce a feeling of rejection towards the retailer and reduce the overall positive influence of control on trust.

> Why did my neighbor get a better price than me? /// The perceived implicit or explicit rule underlying the price differentiation scheme influences its evaluation as well as behavioral reactions. Price differentiation is perceived as more fair and has less dire consequences if people see good reasons for it. Examples for relatively fair pricing rules are discounts for children or senior citizens and quantity rebates, as larger quantities allow companies to incur lower margins per item sold.

\section{$>$ Does the retailer differentiate for pure profit maximiza-} tion or for "more reasonable" motives? /// Lastly and linked to the pricing rule, consumers make inferences about the retailer's motive behind price differentiation. If retailers charge different prices based on cost or performance differences, consumers will be more understanding. This holds also for differences between stationary and digital retailing. Figure 2 shows that the suspected motive of the retailer had the strongest positive association with trust among all tested criteria. Customers do grant companies a certain profit margin as long as they don't feel cheated.

Knowing how to play the game /// In addition to these general observations, our study also revealed considerable heterogeneity among participants, suggesting different seg-

FIGURE 2:

Relative importance of price differentiation criteria for consumer trust

IMPORTANCE FOR TRUST (\%)

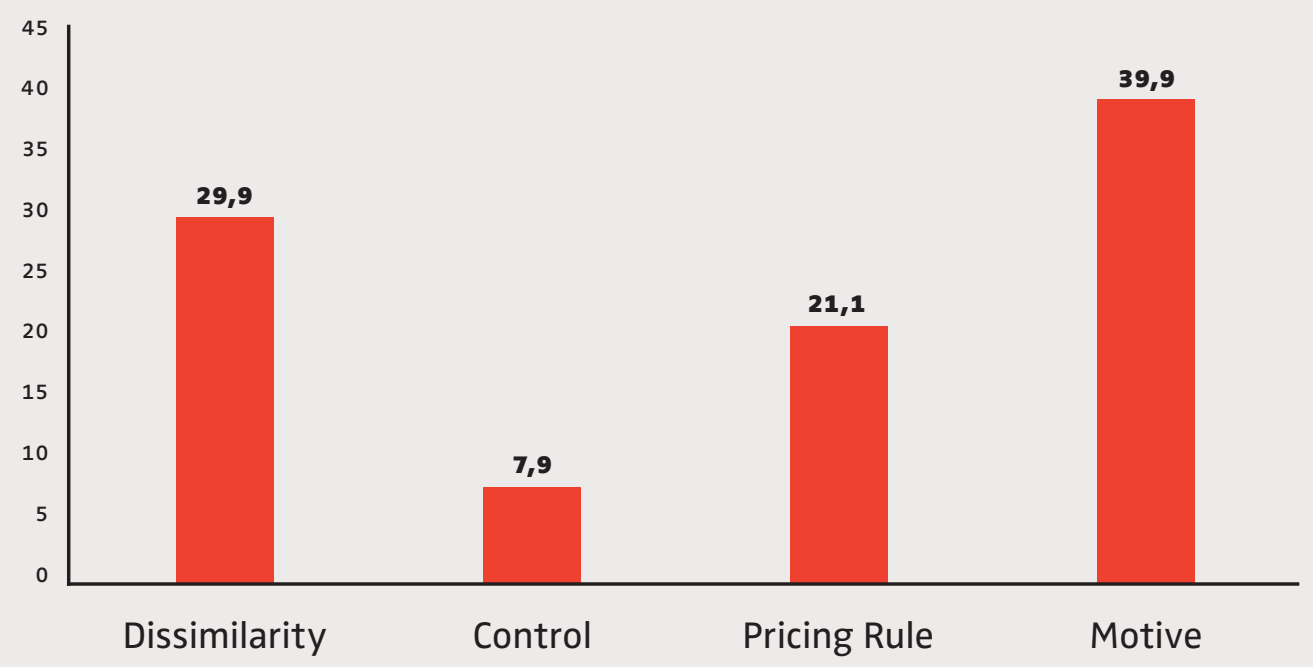


FIGURE 3:

\section{How consumers with high acceptance of price differentiation differ from the rest}

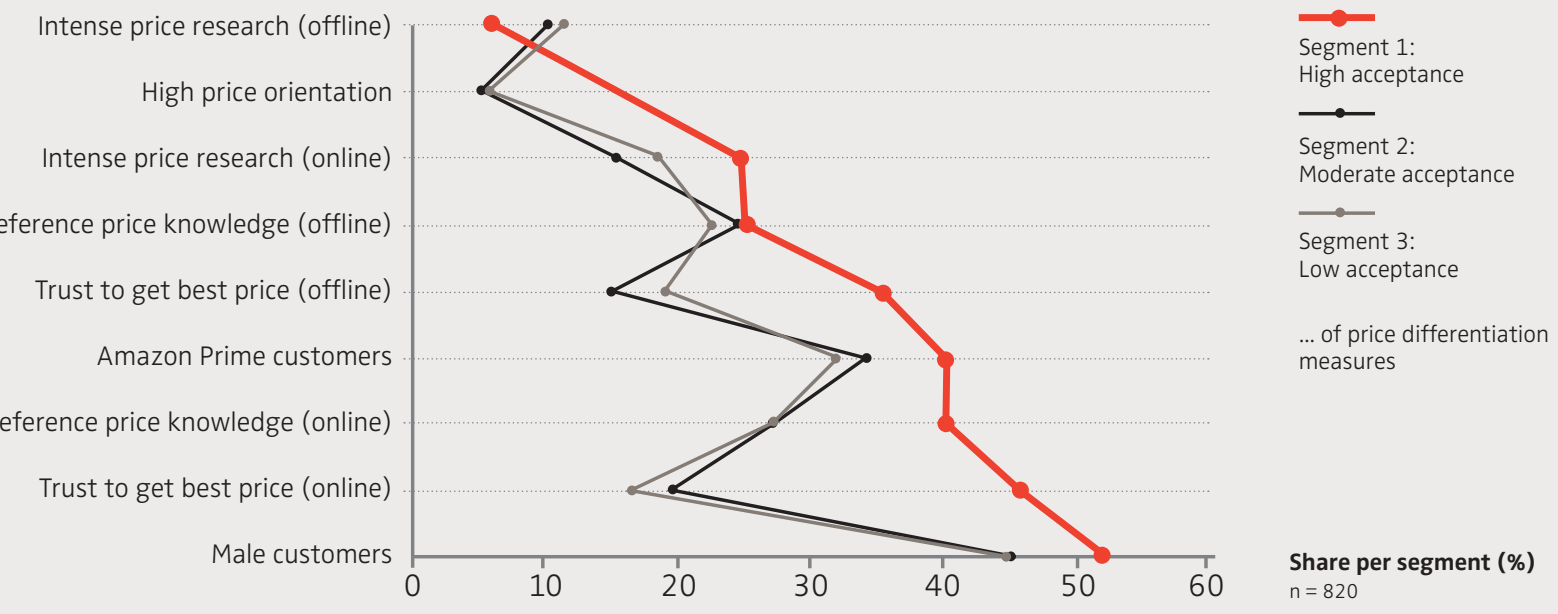

ments based on reactions towards price differentiation. Some participants - making up a substantial portion (27\%) of the market - stand out through significantly more positive reactions towards price differentiation than the rest. This group is particularly well-informed about prices through online channels, leading to increased confidence about their own price expertise and skill to find the best deal (see segment 1 in Figure 3). Obviously, consumers who know how to maneuver through the pricing jungle and are able to land on the "right" side of the spectrum are not as much repelled by differentiation practices. It is therefore reasonable to assume that success in terms of "scoring good deals" plays a significant role in the evaluation of differentiated prices. These assumptions are backed by an analysis of industries in which price differentiation has been common practice for quite some time. For instance, consumers of gas stations find dynamic prices over time - especially within the same day- just as unfair as for any other industry, if they perceive to have been disadvantaged. However, once they profit from the practice, their assessment is significantly more positive than of the same practice in categories like sneakers, perfume, or consumer electronics. We explain this asymmetry by a combination of learned "pricing skills" and control over the final price: Gasoline customers often know the patterns according to which prices fluctuate throughout the day or week. Hence, they can predict and "choose" to get good deals. Their price success lies, at least in part, in their own hands, which lets differentiation schemes shine in a more positive light. Furthermore, others can easily benefit as well, because fluctuating prices are common knowledge and striking a bargain does not require special skills or expertise. Therefore, the rejection based on unfair discrimination of others is low. It is only when consumers feel helplessly at the mercy of the situation - or perceive that others might - that they strongly reject differentiated prices.

To win at price differentiation, retailers need to play fair /// Managers can use these insights to engage in more acceptable methods of price differentiation. After all, feelings of unfair price discrimination can seriously harm trust in the company and damage its reputation. Before implementing differentiation schemes, managers should consider a few aspects. 
》)

\section{Nobody wants to pay}

higher prices for identical or very similar

products, but some have more urgent

needs than striking a good deal.

《

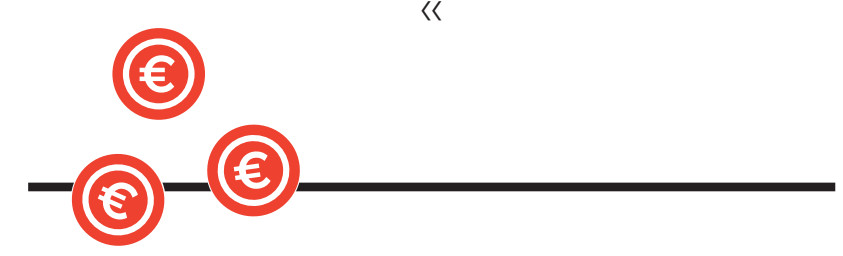

> Appeal to consumers' reward system /// Even in industries where price differentiation is long established, learning effects are not universal and getting a bad price is never acceptable. Rather, consumers need experiences of success. It is critical to show that differentiated prices are not only for the company to skim consumer surplus but may benefit consumers as well. A precondition for this is transparency of the success. Consequently, companies engaging in price differentiation should attempt to make advantages explicit to the target customer. For example, search engines for hotel rooms or airplane seats could point out whether a consumer has paid the lowest price for a room or seat available within the past 30 days.

$>$ Let the wheat separate itself from the chaff /// Pricesensitive consumers are willing to work for their bargain. It is important to give them the opportunity to do so. The slogan should be: Some control, but no free lunch. For example, members of a company's loyalty program give up their personal data in exchange for savings. Our experiments show that consumers who choose not be part of such a program are less dissatisfied when getting a worse deal on products. They could have opted to become a member, which makes them attribute the price difference to their own decision rather than blaming the company for unfair pricing practices. Freemium pricing models work in similar ways: They offer two or more product versions, where customers of the free version must cope with reduced functionality and often third-party advertising. If the difference between perceived benefits and these "costs" remains larger than those of the paid version, consumers will be reluctant to upgrade. On the other hand, less price sensitive consumers have no problem paying for the service.

> Conform to social norms /// Lastly, consumers are more willing to pay a price premium when they believe it to be socially acceptable and not based on managers' greed. When self-selection mechanisms are difficult to implement and offerings at different prices are perceived as very similar, it can help to implement pricing rules that appeal to common decency. For example, public transportation firms often grant discounts for schoolchildren, seniors, and disabled persons, despite offering them the exact same service as regular passengers. Similarly, there are theme parks where customers enjoy free access on their birthday, and residents can visit without charge during one day of the year to compensate for the traffic and noise they endure on the remaining days.

It is a challenge to implement differentiated prices that carry an upside for both consumers and retailers. Not all consumers can benefit from price differentiation on all occasions as this would make differentiation efforts absurd. However, not all need to either. Identifying and addressing price-sensitive customers with good deals is key for the practice to work. Nobody wants to pay higher prices for identical or very similar products, but some have more urgent needs than striking a good deal. Addressing alternative needs, like saving time or effort or contributing to a fair cause can increase willingnessto-pay and create a balanced system of price differentiation.

I.

\title{
FURTHER READING
}

\author{
Reinartz, W.; Haucap, J.; Wiegand, N. \\ and Hunold, M. (2018): \\ "Price Differentiation and
}

Dispersion in Retailing," IFH White Paper, Issue 6, Köln. ISBN: 978-3-935546-82-9 